\title{
Study on the structure vs activity of designed non-precious metal electrocatalysts for $\mathrm{CO}_{2}$ conversion
}

Tingke Rao, Wangchao Yuan, Nivetha Jeyachandran, Azeem Ghulam Nabi, Devis Di Tommaso, and Cristina Giordano ${ }^{a ; *}$ Department of Chemistry, Queen Mary University of London, Mile End Road, London E1 4NS, UK

\section{*c.giordano@gmul.ac.uk}

\begin{abstract}
The rising level of carbon dioxide $\left(\mathrm{CO}_{2}\right)$, mainly a consequence of human activities, it is leading to devastating consequences to our environment and has raised concerns to the public opinion. To face this issue, governments are working to reduce the level of $\mathrm{CO}_{2}$ emissions, whilst the scientific community is focusing to implement the electrochemical conversion of the emitted $\mathrm{CO}_{2}(\mathrm{CO} 2 \mathrm{RR})$ as source of added value chemicals. Due to the high stability of the $\mathrm{CO}_{2}$ molecule, to make its conversion practical, the process requires a suitable electro-catalyst. With the aim to understand the mechanism toward specific CO2RR product and thus increase selectivity, in this contribution, we have explored copper nanoparticles (Cu NPs), as one of the most promising catalyst for $\mathrm{CO}_{2}$ conversion, and investigated the reactivity as a function of selected experimental parameters. The results were rationalized via theoretical investigation, also discussed in the paper, to understand the mechanism behind their activity but, most importantly, to relate structure to selectivity. The Cu NPs, prepared via an unconventional sol-gel process, were shown to be pure, with homogeneous size and morphology, and were tested toward CO2RRs showing a total FE above $90 \%$. The higher FE toward the production of $\mathrm{C}_{2} \mathrm{H}_{4}$ (up to $33 \%$ at an applied potential of $-1.0 \mathrm{~V}$ ) is one of the highest FE reported so far for $\mathrm{Cu}$, without using expensive support. The final products were characterized using X-ray diffraction (XRD) and scanning electron microscopy (SEM).
\end{abstract}




\section{Introduction}

The severe consequences of greenhouse emission to the environment have made the public opinion aware of the importance to find alternative energy sources to the current fossil fuels. The main concerns are toward the high amount of carbon dioxide $\left(\mathrm{CO}_{2}\right)$ in the atmosphere. Alongside strategies aimed at reducing $\mathrm{CO}_{2}$ emission, a complementary approach is its conversion into added value chemicals. In fact, $\mathrm{CO}_{2}$ represents a virtually unlimited source of carbon that may be transformed into a variety of chemicals ${ }^{1}$; these include methanol ${ }^{2,3}$, methane $^{4}$, formic acid ${ }^{5}$, formic acid ester $^{6}$, formamides ${ }^{7}$, carbonic acid esters ${ }^{8}$, carbamic acid esters (urethanes) ${ }^{9}$, lactones ${ }^{10}$, and more, some of which are otherwise produced from fossil sources. However, the $\mathrm{C}=\mathrm{O}$ bond energy $\left(750 \mathrm{~kJ} \mathrm{~mol}^{-1}\right)$ is significantly higher than $\mathrm{C}-\mathrm{C}(336 \mathrm{~kJ}$ $\left.\mathrm{mol}^{-1}\right), \mathrm{C}-\mathrm{O}\left(327 \mathrm{~kJ} \mathrm{~mol}^{-1}\right)$, and $\mathrm{C}-\mathrm{H}\left(411 \mathrm{~kJ} \mathrm{~mol}^{-1}\right)$, making it difficult to convert $\mathrm{CO}_{2}$. Electrocatalysts are required to lower the energy cost of reducing $\mathrm{CO}_{2}$. The efficiency of noble metal-based catalysts such as gold ${ }^{11}$, silver ${ }^{12}$ and palladium ${ }^{13}$ has been demonstrated but these metals are too scarce, making the process not economically feasible. In addition, the process is hardly selective, and many products are formed during the reduction process. To make the process practical, the attention has been focused on finding low-cost non-precious metals alternative, with high selectivity. Several metals have been explored so far including $\mathrm{Ni}^{14}, \mathrm{Co}^{15}, \mathrm{Fe}^{16}, \mathrm{Ti}^{17}, \mathrm{Zn}^{18}, \mathrm{Sn}^{19}, \mathrm{Bi}^{20}$, $\mathrm{Cu}^{21,22}$. Results showed that copper and copper-based materials are the most promising because, beside $\mathrm{CO}$, other more interesting products can be obtained, including the conversion into hydrocarbons ${ }^{23,24,25}$. As a further advantage, the $\mathrm{Cu}$ future supply is not a concern as it is estimated to exceed 5,000 MT (i.e. 200+ years of availability) ${ }^{26}$.

Unfortunately, the overpotential needed by $\mathrm{Cu}$ electrocatalysts for $\mathrm{CO}_{2}$ reduction is very high ${ }^{27}$, while the selectivity is always a problem especially for the formation of $C_{2}$ products (namely $\mathrm{C}_{2} \mathrm{H}_{4}$ and $\mathrm{C}_{2} \mathrm{H}_{6}$ ). For instance, selective production of $\mathrm{C}_{2} \mathrm{H}_{4}$ and $\mathrm{C}_{2} \mathrm{H}_{6}$ have been achieved on nanoporous $\mathrm{Cu}$ film by controlling the morphology which attained a faradic efficiency of $38 \%$ and $46 \%$ at $-1.7 \mathrm{~V}$, respectively. ${ }^{28}$ Despite this research proving the pore depth has an influence on the formation of C2 products, a large overpotential was used, hence lowering the energy efficiency of the reduction process. For this reason, several research are now focusing in optimizing $\mathrm{CO}_{2} \mathrm{RR}$, to 
make it practically but also economically feasible.

Strategies adopted to improve the catalytic activity of $\mathrm{Cu}$ include modification of the surface topology ${ }^{29}$ (to increase the specific surface area and to create more reactive sites), metal doping ${ }^{30,31}$ and alloying ${ }^{32}$ (to promote the adsorption/activation of $\mathrm{CO}_{2}$ and to improve stability), and also nano-structuring ${ }^{33,34}$ (to expose a higher fraction of coordinative corner and edge unsaturated surface atoms). Recent research has also highlighted the superior performance of amorphous nanoparticles compared to crystalline nanoparticles in promoting the transformation of $\mathrm{CO}_{2}$ to profitable formic acid and ethanol ${ }^{35}$. Such an improvement in the catalytic performance has been ascribed to the higher electrochemical surface-active area compared with crystalline nanoparticles that may originate from the higher number of active sites generated from the structural heterogeneity on the amorphous surfaces. However, due to the complexity in structure and difficulties in feature engineering, few studies have been conducted on the catalytic performance of amorphous compounds.

This finding significantly increases the interest in the tailored synthesis of $\mathrm{Cu}$ nanoparticles with fine control over the degree of crystallinity, alongside size and porosity. The synthetic methodology to prepare $\mathrm{Cu}$ nanoparticles is, therefore, of critical importance to maximize catalytic activity and selectivity toward a specific product. It is surprising that not much attention has been devoted to optimizing such a key step. $\mathrm{Cu}$ nanoparticles have been prepared for different applications, using selected pathways, e.g. via microwave ${ }^{36}$ or electron beam irradiation ${ }^{37}$, bio-synthesis ${ }^{38}$ and laser ablation ${ }^{39}$. Since $\mathrm{Cu}$ is easily aggregated and oxidized, many researchers synthesize Cu nanoparticles capped with polymers, such as PVP (poly vinyl pyrrolidone) and gelatin ${ }^{40,41}$. However, polymers cannot be decomposed easily so the remaining polymers might affect catalytic performances. Alternatively, surfactants can be used for this process since they decompose more easily than polymers because of their lower molecular masses. Other researchers used strong reducing agents, such as hydrazine and sodium borohydride, to synthesize $\mathrm{Cu}$ nanoparticles with surfactants, such as CTAB (cetyl trimethyl ammonium bromide), SDS (sodium dodecyl sulfate), thiol and carboxylic acid ${ }^{42,43}$. However, hydrazine is extremely toxic and dangerous, and sodium borohydride will produce impurities, such as boron and sodium salts, which are difficult to remove by solvent washing. Kim et al. managed to synthesize 
monodispersed copper nanoparticles without the use of strong reducing agents by using thermal decomposition of $\mathrm{Cu}$-oleate complex, which was prepared by the reaction of $\mathrm{CuCl}_{2}$ with aqueous sodium oleate. However, this method required very low pressure $(0.3 \text { torr })^{44}$.

The present contribution introduces an alternative, easy to use, and green (nontoxic) synthetic methodology for phase-pure, monodispersed $\mathrm{Cu}$ particles with different crystallinity. A sol-gel based procedure called urea glass route ${ }^{45}$ was tailored for the first time for the preparation of pure copper particles.

The as-prepared particles were tested for the electrochemical $\mathrm{CO}_{2}$ reduction reaction $\left(\mathrm{CO}_{2} \mathrm{RR}\right)$ and showed ability towards the formation of highly valuable ethylene rather than $\mathrm{CO}$ and $\mathrm{CH}_{4}$ production, already at $-1.0 \mathrm{~V}$ applied potential ( $v s \mathrm{RHE}$ ), with the catalyst not undergoing conversion, thus showing high stability. These catalytic findings were rationalized by density functional calculations of the processes controlling the adsorption and mechanism of $\mathrm{CO}_{2}$ formation.

\section{Methods}
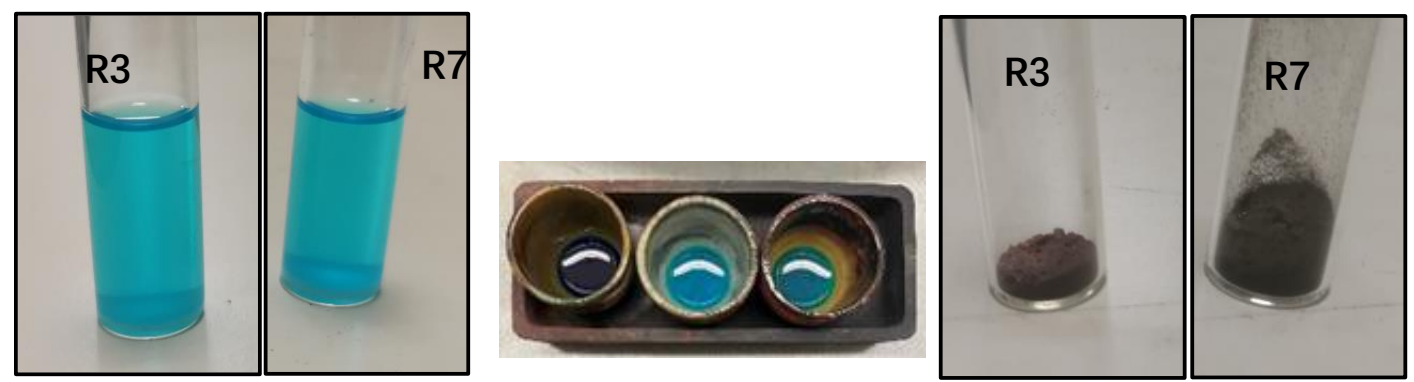

Figure 1. From left to right, solutions of $\mathrm{Cu}$-Urea in ethanol with different urea-metal ratio $(\mathrm{R})$; corresponding products after solvent evaporation and heat treatment under $\mathrm{N}_{2}$ flow at $350^{\circ} \mathrm{C}$.

\section{Synthesis of Cu Nanoparticles}

$\mathrm{Cu}$ nanoparticles were synthesized by modification of a typical urea glass route methodology ${ }^{45}$. Copper(II) nitrate hydrate (CAS Number 13778-31-9, 99.999\% trace metals basis) and urea (CAS 57-13-6, ACS, Reag. Ph Eur) were purchased from SigmaAldrich, Inc. Samples with different urea/Cu salt molar ratio (R) were prepared to investigate the influence of the urea amount over nanoparticles crystallinity and/or size. In a standard synthesis, copper nitrate and suitable amount of urea (depending on the final R) were dissolved ethanol to form a homogeneous solution (figure 1.A). 
The solution was stirred for 24 hours and the mixture then transferred into a crucible and the solvent was let to evaporate. The resulting product was a blue fused phase (figure 1.B). This "fused" phase was heat treated under nitrogen flow up to $350^{\circ} \mathrm{C}$. This temperature was found to be ideal to achieve phase pure particles. Lower temperatures lead to a mixture of metallic copper and copper oxides (see figure SI.1), while samples treated at higher temperature are a mixture of different products (data not shown). After cooling down to room temperature, a brown powder was obtained (figure 1.C).

\section{Preparation of Electrocatalysts}

$5 \mathrm{mg}$ of the synthesized $\mathrm{Cu}$ particles were dispersed in a mixed aqueous solution of $750 \mu \mathrm{L}$ deionized water, $200 \mu \mathrm{L}$ ethanol and $50 \mu \mathrm{L}$ Nafion solution (CAS 31175-20-9, Sigma-Aldrich). The mixture suspension was ultrasonicated to obtain a homogeneous ink. Polished graphite discs ( $\varnothing=10 \mathrm{~mm}$, Ted Pella) served as substrates for all the catalysts. They were polished to a mirror-like finish using SiC paper (grit 1200, Struers) followed by diamond slurries (Diapro 9 and $3 \mu \mathrm{m}$ Struers). The Cu particle ink was then drop cast on the graphite with a loading of $325 \mu \mathrm{g} / \mathrm{cm}^{2}$. The catalyst was dried under a heat lamp and used for the electrochemical reactions.

\section{Electrochemical Setup}

Identification and quantification of the $\mathrm{CO}_{2}$ reduction products was achieved using a custom-built gastight Teflon electrochemical cell based on the design of Kuhl et al. ${ }^{23}$ 
(Figure 2) where the counter electrode is a graphite rod. Details of the experimental procedure are reported in the SI.

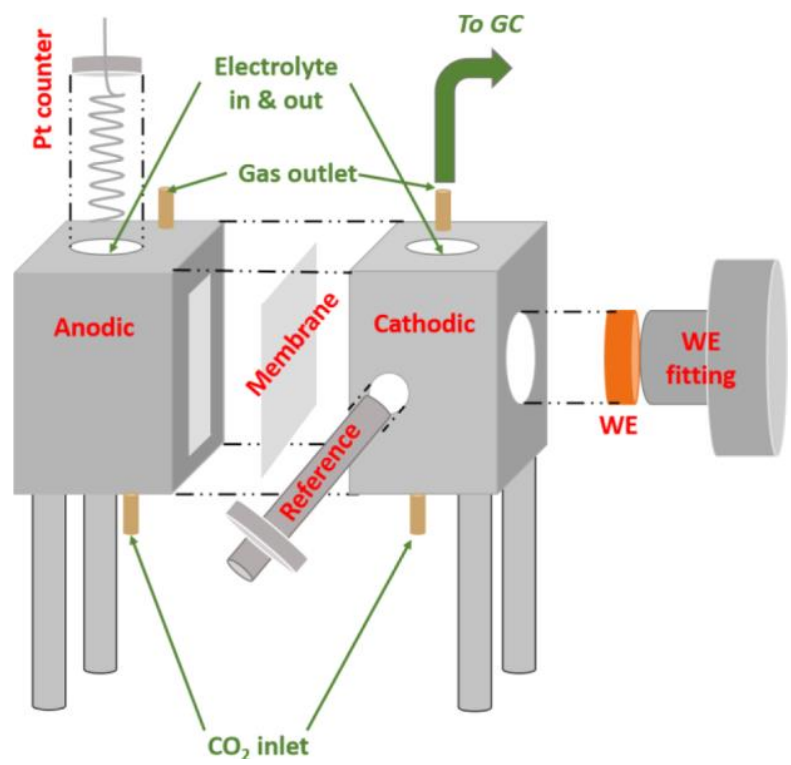

Figure 2. Schematic diagram of the electrochemical cell used for $\mathrm{CO}_{2}$ electro-reduction (WE: Working Electrode).

\section{Computational Details}

We have used density functional theory (DFT) calculations to rationalize the experimentally observed distribution of products from the $\mathrm{CO}_{2}$ reduction reaction on $\mathrm{Cu}$. All calculations were conducted with the Vienna Ab initio Simulation Package" (VASP) using the following computational settings: Perdew-Burke-Ernzerhof (PBE) exchange correlation functional with the Grimme's-D3 dispersion correction; planewave (PW) basis set within the framework of the projector augmented wave method with a PW cutoff of $450 \mathrm{eV}$; Monkhorst-Pack $k$-point samplings of $(5 \times 5 \times 1)$. We have computed the adsorption of the $\mathrm{CO}_{2}$ and the experimentally observed molecules on the low index $\mathrm{Cu}(100),(110)$, and (111) surfaces. These surfaces were represented by $3 \times 3$ (for C1 molecules) or 4x4 (for C2 molecules) slab models with four Cu layers and a vacuum of $15 \AA$. The adsorption energy, $E_{a d s}$, of a species on the Cu surface or cluster was computed according to the expression $E_{a d s}=E_{\text {surf }+ \text { mol }}-\left(E_{\text {surf }}+E_{\text {mol }}\right)$, where $E_{\text {surf }+m o l}$ is the total energy of the adsorbate-substrate system, $E_{\text {surf }}$ is the energy of the slab, and $E_{m o l}$ is the energy of the isolated $\mathrm{CO}_{2}$ molecule. Transition states (TS) were determined using the nudge elastic band method in VASP. 


\section{Result Discussion}

\section{Structural characterization}

Phase attribution of as-prepared samples was achieved by XRD investigation. Figure 3 shows the samples prepared with two different urea/Cu salt molar ratio $(R)$ and treated at $350^{\circ} \mathrm{C}$. In both cases, the expected crystal structure of pure metallic (cubic) $\mathrm{Cu}$ is achieved and no other crystalline phase is observed, including carbon (expected peak at $26^{\circ}$ ), a typical side product when urea is used. A closer look at the patterns shows that the peaks of the prepared Cu samples at $43^{\circ}(111)$ and $50^{\circ}(200)$, regardless of the $\mathrm{R}$ value, are slightly shifted to higher angles compared to the expected pattern, indicating a slightly contracted structure, possibly due to the nano-sized nature of the material. The effect on $\mathrm{R}$ is more pronounced on the peak broadness (FWHM), which increases going from $\mathrm{R}=3$ to $\mathrm{R}=7$, indicating either smaller sizes or a lower degree of crystallinity in the sample prepared with $\mathrm{R}=7$ (i.e. using higher urea/Cu salt ratio). We can speculate that an excess of urea, which implies

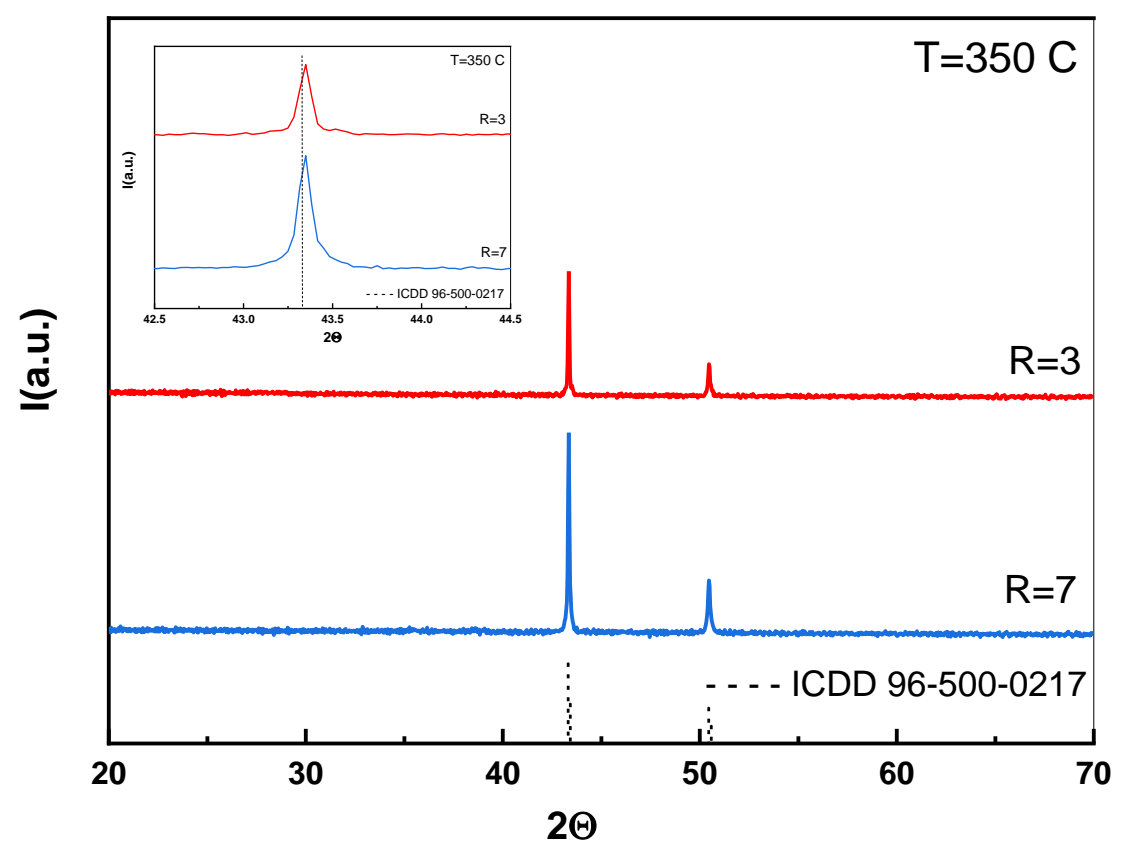

Figure 3. XRD patterns of $\mathrm{Cu}$ samples prepared with different Urea/Cu molar ratio and treated at $350^{\circ} \mathrm{C}$. The expected pattern for pure $\mathrm{Cu}^{\circ}$ (ICCD 96-950-0217) is also reported (dashed vertical lines) for comparison.

the formation of a larger amount of N-rich matrix (where the matrix is the result of the urea polymerization process REF) that "contrast" nanoparticles coalescence and growth. However, further studies are in progress to confirm this point. 
Results from the X-rays study are reported in Table 1.

Table 1. Results from the X-rays study on the prepared samples.

\begin{tabular}{|l|l|l|l|l|}
\hline $\begin{array}{l}\text { Sample } \\
\text { Name }\end{array}$ & $\begin{array}{l}\mathbf{R} \\
\text { (Urea/Metal) }\end{array}$ & $\begin{array}{l}\text { FWHM } \\
\mathbf{2 \theta}\end{array}$ & $\begin{array}{l}\text { Diameter } \\
\mathbf{( n m})\end{array}$ & $\begin{array}{l}\text { Phase attribution } \\
\text { by XRD }\end{array}$ \\
\hline Cu R3 & 3 & 0.08 & 112 & Cu \\
Cu R7 & 7 & 0.09 & 99 & (ICCD 96-500-0217) \\
\hline
\end{tabular}

To have information on the morphology of the particles and general homogeneity, a SEM study was performed. A SEM image of sample prepared with $R=3$ and $R=7$ and treated at $350^{\circ} \mathrm{C}$ is reported in Figure 4. From this figure it can be observed that for $\mathrm{R}=3$ sample, small spheroidal nanoparticles are interconnected forming a rather homogeneous network, while for $\mathrm{R}=7$ a higher homogeneity and smaller particles
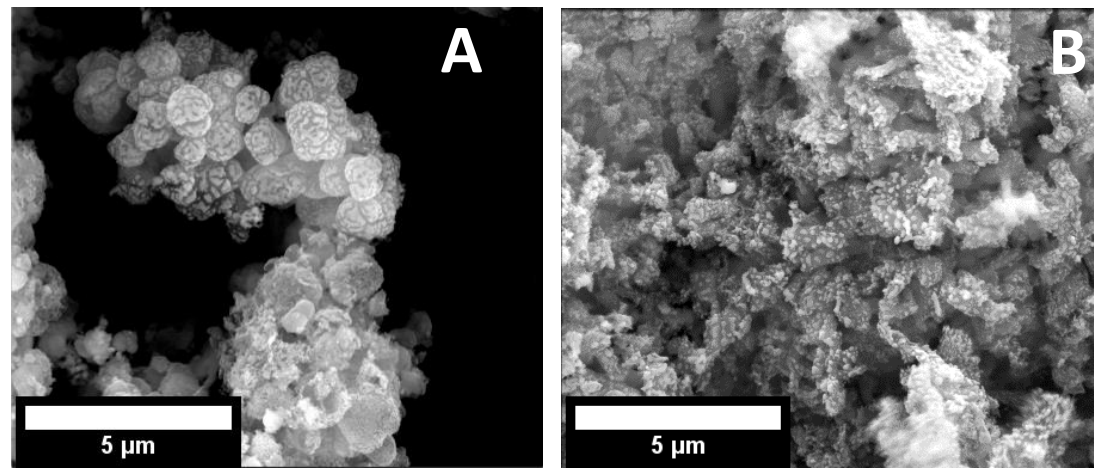

Figure 4. SEM images of A) CuU3, B) CuU7 synthesized at $350^{\circ} \mathrm{C}$.

dimension ( $99 \mathrm{~nm}$ ) can be observed (compared to $\mathrm{R}=3 ; 112 \mathrm{~nm}$ ). This is in line with what observed from XRD where we the pattern for sample prepared by $\mathrm{R}=7$ showed broader peaks (i.e. smaller sizes or lower degrees of crystallinity) compared to sample prepared with $\mathrm{R}=3$.

\section{$\mathrm{CO}_{2}$ reduction reaction}

The Cu particles were tested for $\mathrm{CO}_{2} \mathrm{RR}$ at different applied potential versus RHE (Table 2). Interesting, the major products on both catalysts was neither $\mathrm{CO}$ nor $\mathrm{HCOO}^{-}$but $\mathrm{C}_{2} \mathrm{H}_{4}$ (alongside $\mathrm{H}_{2}$, from the competitive RHE reaction). The observed FE for ethylene 
$\left(\mathrm{C}_{2} \mathrm{H}_{4}\right)$ is up to $33 \%$ for an applied potential of $-1.0 \mathrm{~V}$, one of the highest values reported in literature so far for pure Cu particles (Table 3). Moreover, the FE of $\mathrm{C}_{2} \mathrm{H}_{4}$ at $-1.0 \mathrm{~V}$ is almost seven times higher than $\mathrm{CH}_{4}$. In comparison, the $\mathrm{FE}\left(\mathrm{C}_{2} \mathrm{H}_{4}\right) / \mathrm{FE}\left(\mathrm{CH}_{4}\right) \approx 1$ on polycrystalline copper ${ }^{23}$. This is an important result because the $\mathrm{CO}_{2}$ conversion to ethylene is a highly profitable process: $\mathrm{C}_{2} \mathrm{H}_{4}$ is a feedstock for many various products and represents the most important organic chemical by tonnage manufactured. In comparison, natural gas market prices put constraints on the methane market price ${ }^{46}$. From Table 2, we can also observe that regardless of the catalyst used ( $R=3$ or $R=7$ ), the more negative is the applied potential, the lower is the FE of $\mathrm{CO}$ and $\mathrm{HCOO}^{-}$, while the FE for $\mathrm{CH}_{4}$ increases. No trend is observed for $\mathrm{C}_{2} \mathrm{H}_{4}$, ethanol and n-propanol, with Ethanol displaying the highest FE for an applied potential of $-1.0 \mathrm{~V}$.

Table 2. Faradaic efficiencies ( $\mathrm{FE}$ ) of $\mathrm{CO}_{2}$ reduction reaction under different applied potentials.

\begin{tabular}{|c|c|c|c|c|c|c|c|c|c|}
\hline \multicolumn{10}{|c|}{ Cu $R=3$} \\
\hline $\begin{array}{l}\text { E (V } \\
\text { vs } \\
\text { RHE) }\end{array}$ & $\begin{array}{l}\text { jtotal } \\
\left(\mathrm{mA} / \mathrm{cm}^{2}\right)\end{array}$ & $\begin{array}{l}\mathrm{FE} \\
\left(\mathrm{H}_{2}\right)\end{array}$ & $\begin{array}{l}\mathrm{FE} \\
\text { (CO) }\end{array}$ & $\begin{array}{l}\text { FE } \\
\text { (HCOO-) }\end{array}$ & $\begin{array}{l}\mathrm{FE} \\
\left(\mathrm{CH}_{4}\right)\end{array}$ & $\begin{array}{l}\mathrm{FE} \\
\left(\mathrm{C}_{2} \mathrm{H}_{4}\right)\end{array}$ & $\begin{array}{l}\text { FE } \\
\text { (EtOH) }\end{array}$ & $\begin{array}{l}\text { FE } \\
\text { (PrOH) }\end{array}$ & $\begin{array}{l}\text { Total } \\
\text { FE }\end{array}$ \\
\hline-0.9 & -5.1 & 45.0 & 6.3 & 8.0 & 0.4 & 18.9 & 4.1 & 3.5 & 89.6 \\
\hline-1.0 & -9.3 & 33.0 & 1. 4 & 5.0 & 4.9 & 32.6 & 9.2 & 3.7 & 92.9 \\
\hline-1.1 & -22.6 & 40.0 & $0.7^{\nabla}$ & $1.4 \nabla$ & $18.4 \nabla$ & 25.4 & 7.4 & 1.0 & 95.8 \\
\hline \multicolumn{10}{|c|}{ Cu $R=7$} \\
\hline $\begin{array}{l}\text { E (V } \\
\text { vs } \\
\text { RHE) }\end{array}$ & $\begin{array}{l}\text { jtotal } \\
\left(\mathrm{mA} / \mathrm{cm}^{2}\right)\end{array}$ & $\begin{array}{l}\mathrm{FE} \\
\left(\mathrm{H}_{2}\right)\end{array}$ & $\begin{array}{l}\mathrm{FE} \\
\text { (CO) }\end{array}$ & $\begin{array}{l}\text { FE } \\
\left(\mathrm{HCOO}^{-}\right)\end{array}$ & $\begin{array}{l}\mathrm{FE} \\
\left(\mathrm{CH}_{4}\right)\end{array}$ & $\begin{array}{l}\mathrm{FE} \\
\left(\mathrm{C}_{2} \mathrm{H}_{4}\right)\end{array}$ & $\begin{array}{l}\text { FE } \\
\text { (EtOH) }\end{array}$ & $\begin{array}{l}\text { FE } \\
\text { (PrOH) }\end{array}$ & $\begin{array}{l}\text { Total } \\
\text { FE }\end{array}$ \\
\hline-0.9 & -3.6 & 56.8 & 8.9 & 5.4 & N.D* & 12.0 & 3.8 & 2.1 & 91.4 \\
\hline-1.0 & -6.5 & 32.4 & 3.9 & 4.6 & 5.8 & 29.8 & 7.2 & 3.1 & 90.7 \\
\hline-1.1 & -16.4 & 54.9 & $1.0 \nabla$ & $1.7 \downarrow$ & $13.2 \nabla$ & 17.9 & 6.1 & 0.9 & 96.9 \\
\hline
\end{tabular}


${ }^{*}$ N.D. $=$ not detected. EtOH $=$ Ethanol, $\mathrm{PrOH}=n-$ Propanol.

To rationalize the preferential conversion $\mathrm{CO}_{2}$ to molecular hydrogen and ethylene, we have computed the adsorption of $\mathrm{H}_{2} \mathrm{O}$ and $\mathrm{CO}_{2}$ on the $\mathrm{Cu}(100),(110)$, and (111) surfaces and of the molecules resulting from their reduction reaction: $\mathrm{H}_{2}, \mathrm{CO}, \mathrm{HCOO}^{-}$, $\mathrm{CH}_{4}, \mathrm{C}_{2} \mathrm{H}_{4}, \mathrm{EtOH}$, and PrOH (Table 4). The $\mathrm{H}_{2} \mathrm{O}$ and $\mathrm{CO}_{2}$ molecules have similar binding strength with values adsorption energies $\left(E_{\text {ads }}\right)$ between $-0.44 \mathrm{eV}$ and $-0.65 \mathrm{eV}$, depending on the surface considered. However, $\mathrm{H}_{2}$ has an adsorption energy of approximately $-0.1 \mathrm{eV}$, which corresponds to a significantly weaker surface binding than ${ }^{*} \mathrm{COOH}$ and ${ }^{*} \mathrm{CO}$, the first two intermediates in the $\mathrm{CO}_{2} \mathrm{RR}$ reaction pathway ${ }^{47}$. Therefore, $\mathrm{H}_{2}$ desorbs more easily than $\mathrm{COOH}$ and $\mathrm{CO}$, leading to the observed high $\mathrm{FE}$ of $\mathrm{H}_{2}$ (Table 2 ) due to the competitive hydrogen evolution reaction $\left(2 \mathrm{H}^{+}+2 \mathrm{e}^{-} \rightarrow \mathrm{H}_{2}\right.$ ).

Table 3: Comparison of the Faradaic efficiency (FA) of ethylene on Cu nano-catalysts used for $\mathrm{CO}_{2} \mathrm{RR}$ reported in literature.

\begin{tabular}{|c|c|c|c|c|c|}
\hline Composition & Support & Electrolyte & Potential (V) & $\begin{array}{l}\mathrm{FE}(\%) \\
\mathrm{C}_{2} \mathrm{H}_{4}\end{array}$ & Ref \\
\hline Cu NPs & Graphite & $0.1 \mathrm{M} \mathrm{KHCO}_{3}$ & $-1.0 \mathrm{~V}$ vs. RHE & $\sim 33$ & This paper \\
\hline Cu film & - & $1 \mathrm{M} \mathrm{KHCO}_{3}$ & $-0.5 \mathrm{~V}$ vs. RHE & 40 & 48 \\
\hline Cu porous & $\begin{array}{c}\text { Template } \\
\mathrm{Al}_{2} \mathrm{O}_{3}\end{array}$ & $0.1 \mathrm{M} \mathrm{KHCO}_{3}$ & $\mathrm{~N} / \mathrm{R}$ & 38 & 28 \\
\hline Cu NPs & Carbon & $0.5 \mathrm{M} \mathrm{KHCO}_{3}$ & $-1.1 \mathrm{~V}$ vs. RHE & 6.3 & 49 \\
\hline Cu NPs & SWCNTs & $0.1 \mathrm{M} \mathrm{KHCO}_{3}$ & $0.9 \mathrm{~V}$ vs. RHE & 41 & $\begin{array}{c}118 \text { our } \\
\text { table }\end{array}$ \\
\hline Cu NPS & $\mathrm{MoS}_{2}$ & $0.1 \mathrm{M} \mathrm{KHCO}_{3}$ & -1.4 V vs SCE & 2 & $\begin{array}{c}121 \text { our } \\
\text { table }\end{array}$ \\
\hline Cu NPs & - & $0.1 \mathrm{M} \mathrm{KHCO}_{3}$ & $\begin{array}{l}-1.8 \mathrm{~V} \text { vs } \\
\mathrm{Ag} / \mathrm{AgCl}\end{array}$ & 44 & 50 \\
\hline $\begin{array}{c}\text { Cu NP } \\
\text { ensemble }\end{array}$ & Carbon & $0.1 \mathrm{M} \mathrm{KHCO}_{3}$ & $\begin{array}{c}-0.86 \text { V vs. } \\
\text { RHE }\end{array}$ & 33.2 & 22 \\
\hline $\begin{array}{c}\mathrm{Cu} \\
\text { nanocrystals } \\
(44 \mathrm{~nm})\end{array}$ & Carbon & $0.1 \mathrm{M} \mathrm{KHCO}_{3}$ & $-1.1 \mathrm{~V}$ vs. RHE & 41 & 51 \\
\hline $\begin{array}{c}\mathrm{Cu} \\
\text { nanocubes }\end{array}$ & - & $10 \mathrm{M} \mathrm{KOH}$ & -0.8 V vs. RHE & 60 & 52 \\
\hline
\end{tabular}




\begin{tabular}{|c|c|c|c|c|c|}
\hline$(70 \mathrm{~nm})$ & & & & & \\
\hline Cu NPs & - & $0.1 \mathrm{M} \mathrm{KHCO}_{3}$ & $\begin{array}{c}-1.11 \text { V vs. } \\
\text { RHE }\end{array}$ & 41.1 & 53 \\
\hline $\begin{array}{c}\text { Prism } \\
\text { shaped } \mathrm{Cu}\end{array}$ & - & $0.1 \mathrm{M} \mathrm{KHCO}_{3}$ & $\begin{array}{c}-1.16 \text { V vs. } \\
\text { RHE }\end{array}$ & $\sim 29$ & 54 \\
\hline $\begin{array}{c}\text { Twinned } \mathrm{Cu} \\
\text { nanowire }\end{array}$ & Carbon & $0.1 \mathrm{M} \mathrm{KHCO}_{3}$ & $-1.0 \mathrm{~V}$ vs. RHE & $<5$ & 25 \\
\hline Cu NPs & $\begin{array}{l}\text { Vulcan } \\
\text { Carbon }\end{array}$ & $0.1 \mathrm{M} \mathrm{KHCO}_{3}$ & $-2.2 \mathrm{~V}$ vs. RHE & $\sim 42$ & 55 \\
\hline $\begin{array}{c}\text { Cu NPs } \\
\text { dispersed } \\
\text { carbon } \\
\text { aerogels }\end{array}$ & Carbon & $0.1 \mathrm{M} \mathrm{KHCO}_{3}$ & $-0.6 \mathrm{~V}$ vs. RHE & 15.83 & 21 \\
\hline $\begin{array}{c}\text { Star } \\
\text { Decahedron- } \\
\text { Cu NPs }\end{array}$ & - & $0.1 \mathrm{M} \mathrm{KHCO}_{3}$ & $\begin{array}{c}-0.99 \vee v s . \\
\text { RHE }\end{array}$ & $52.43 \pm 2.72$ & 56 \\
\hline $\begin{array}{c}\text { Commercial } \\
\text { Cu NPs }\end{array}$ & - & $0.1 \mathrm{M} \mathrm{KHCO}_{3}$ & $\begin{array}{c}-1.01 \text { V vs. } \\
\text { RHE }\end{array}$ & $37.08 \pm 6.87$ & 56 \\
\hline
\end{tabular}

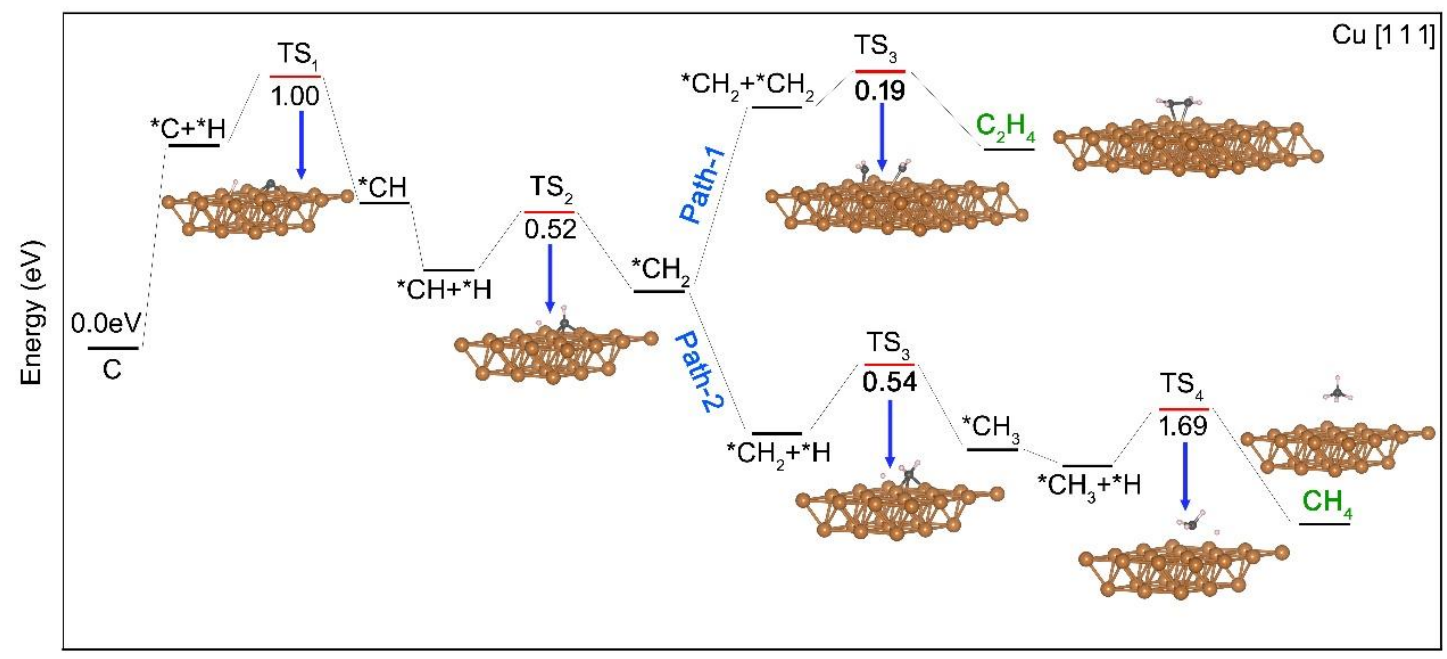

Reaction Coordinate

Figure 4. The energy profiles for the competitive reaction pathways for $\mathrm{C}_{2} \mathrm{H}_{4}$ (Path-1) and $\mathrm{CH}_{4}$ (Path-2) formation on the $\mathrm{Cu}(111)$ surface.

For the other CO2RR products, ethylene is the most stable species on the copper surfaces because of the ability of the $\mathrm{H}_{2} \mathrm{C}=\mathrm{CH}_{2}$ molecule to form $\pi$ bonding interactions with the copper surface, which $\mathrm{CH}_{4}$, and other $\mathrm{Csp}^{3}$ hybridized molecules (EtOH, $\mathrm{PrOH}$ ) are unable to form (Figure SI.4 in ESI). Calculation of two competitive energy pathways for the formation of $\mathrm{CH}_{4}$ and $\mathrm{C}_{2} \mathrm{H}_{4}$ starting from the ${ }^{*} \mathrm{CH}_{2}$ intermediate on the $\mathrm{Cu}(111)$ 
surface (Figure 4) shows that the $\mathrm{CH}_{2}$-to- $\mathrm{CH}_{3}$ reaction has an activation barrier of 0.19 $\mathrm{eV}$ (path-2), while the dimerization of ${ }^{*} \mathrm{CH}_{2}$ to form $\mathrm{C}_{2} \mathrm{H}_{4}$ has an activation energy of $0.19 \mathrm{eV}$ (path-1). Moreover, the reaction energy (enthalpy) for $\mathrm{C}_{2} \mathrm{H}_{4}(-1.81 \mathrm{eV})$ is more exergonic than $\mathrm{CH}_{4}(-1.09 \mathrm{eV})$. Hence, these results suggest that both thermodynamic and kinetic factors contribute to the higher FE of $\mathrm{C}_{2} \mathrm{H}_{4}$ compared to $\mathrm{CH}_{4}$. The reaction pathway on the $\mathrm{Cu}(100)$ surface gave slightly different energetics (Figure SI.5 in ESI), but still provides similar conclusions.

Table 4: Adsorption energies on Cu surfaces. Values in eV.

\begin{tabular}{|c|c|c|c|}
\hline $\mathrm{Cu}$ & $\left(\begin{array}{lll}1 & 0 & 0\end{array}\right)$ & $\left(\begin{array}{lll}1 & 1 & 0\end{array}\right)$ & $\left(\begin{array}{lll}1 & 1 & 1\end{array}\right)$ \\
\hline $\mathrm{H}_{2} \mathrm{O}$ & -0.54 & -0.65 & -0.44 \\
\hline $\mathrm{H}_{2}$ & -0.13 & -0.11 & -0.13 \\
\hline $\mathrm{CO}_{2}$ & -0.60 & -0.61 & -0.58 \\
\hline $\mathrm{CO}$ & -1.08 & -1.50 & -1.22 \\
\hline $\mathrm{COOH}$ & -2.57 & -3.75 & -1.72 \\
\hline $\mathrm{CH}_{4}$ & -0.23 & -0.22 & -0.28 \\
\hline $\mathrm{C}_{2} \mathrm{H}_{4}$ & -0.85 & -1.02 & -0.69 \\
\hline EtOH & -0.50 & -0.45 & -0.48 \\
\hline PrOH & -0.60 & -0.51 & -0.57 \\
\hline
\end{tabular}

\section{Conclusion}

Cu particles phase pure and with homogeneous morphology were synthesized for the first time by a sol-gel process called urea-glass-route. The particles were tested toward $\mathrm{CO}_{2} \mathrm{RRs}$ showing a total $\mathrm{FE}$ above $90 \%$. The higher $\mathrm{FE}$ toward the production of $\mathrm{C}_{2} \mathrm{H}_{4}$ with a faradaic efficiency up to $33 \%$ at an applied potential of $-1.0 \mathrm{~V}$, one of the highest FE reported so far, without using expensive support. Interesting, the $\mathrm{FE}_{\mathrm{co}}$ and $\mathrm{FE}_{\mathrm{HCOO}}$ decrease, when a more negative potential is applied, while for production of methane, a more negative applied potential (-1.1V versus RHE) was proved to be the most suitable.

\section{Acknowledgements}

All authors would like to thank Dr Louisa Rui Lin Ting and Prof. Boon Siang Yeo from Seoul National University for useful discussion in the preparation of this manuscript. We are grateful to the UK Materials and Molecular Modelling Hub for computational resources, which is partially funded by EPSRC (EP/P020194/1). Via our membership of 
the UK's HEC Materials Chemistry Consortium, which is funded by EPSRC (EP/L000202), this work used the ARCHER UK National Supercomputing Service

(http://www.archer.ac.uk). This research utilized Queen Mary's Apocrita HPC facility, supported by QMUL Research-IT. http://doi.org/10.5281/zenodo.438045

\section{References}

(1) Omae, I. Aspects of Carbon Dioxide Utilization. Catalysis Today 2006, 115 (1-4), 3352. https://doi.org/10.1016/j.cattod.2006.02.024.

(2) Aziz, M. A. A.; Jalil, A. A.; Triwahyono, S.; Ahmad, A. CO 2 Methanation over Heterogeneous Catalysts: Recent Progress and Future Prospects. Green Chem. 2015, 17(5), 2647-2663. https://doi.org/10.1039/C5GC00119F.

(3) Inui, T.; Takeguchi, T. Effective Conversion of Carbon Dioxide and Hydrogen to Hydrocarbons. Catalysis Today 1991, 10 (1), 95-106. https://doi.org/10.1016/09205861(91)80077-M.

(4) Tominaga, K.; Sasaki, Y.; Kawai, M.; Watanabe, T.; Saito, M. Ruthenium Complex Catalysed Hydrogenation of Carbon Dioxide to Carbon Monoxide, Methanol and Methane. Journal of the Chemical Society, Chemical Communications 1993, No. 7, 629. https://doi.org/10.1039/c39930000629.

(5) Gassner, F.; Leitner, W. Hydrogenation of Carbon Dioxide to Formic Acid Using WaterSoluble Rhodium Catalysts. Journal of The Chemical Society 1993, 19, 1465-1466. https://doi.org/10.1039/b804327b.

(6) Darensbourg, D. J.; Ovalles, C. Anionic Group 6B Metal Carbonyls as Homogeneous Catalysts for Carbon Dioxide/Hydrogen Activation. The Production of Alkyl Formates. Journal of the American Chemical Society 1984, 106 (13), 3750-3754. https://doi.org/10.1021/ja00325a007.

(7) Kayaki, Y. Water-Soluble Trialkylphosphine-Ruthenium(II) Complexes as Efficient Catalysts for Hydrogenation of Supercritical Carbon Dioxide Utilization of Supercritical $\mathrm{CO} 2$ as a Reaction Medium View Project Molecular Catalysis for CO2 Fixation View Project. 2001, 34 (7), 1119-1122. https://doi.org/10.1246/cl.2001.1016.

(8) Choi, J.-C.; He, L.-N.; Yasuda, H.; Sakakura, T. Selective and High Yield Synthesis of Dimethyl Carbonate Directly from Carbon Dioxide and Methanol. Green Chemistry 2002, 4 (3), 230-234. https://doi.org/10.1039/b200623p.

(9) Yoshida, M.; Hara, N.; Okuyama, S. Catalytic Production of Urethanes from Amines and Alkyl Halides in Supercritical Carbon Dioxide. Chemical Communications 2000, No. 2 , 151-152. https://doi.org/10.1039/a908819i.

(10) Reetz, M. T.; Fox, D. N. A. Carbon-Carbon Bond Formation Catalyzed by Lithium Perchlorate in Dichloromethane. Tetrahedron Letters 1993, 34 (7), 1119-1122. https://doi.org/10.1016/S0040-4039(00)77505-8.

(11) Zhu, W.; Michalsky, R.; Metin, Ö.; Lv, H.; Guo, S.; Wright, C. J.; Sun, X.; Peterson, A. A.; Sun, S. Monodisperse Au Nanoparticles for Selective Electrocatalytic Reduction of CO 2 to CO. J. Am. Chem. Soc. 2013, 135 (45), 16833-16836. https://doi.org/10.1021/ja409445p.

(12) Kim, C.; Jeon, H. S.; Eom, T.; Jee, M. S.; Kim, H.; Friend, C. M.; Min, B. K.; Hwang, Y. J. Achieving Selective and Efficient Electrocatalytic Activity for $\mathrm{CO}_{2}$ Reduction Using Immobilized Silver Nanoparticles. J. Am. Chem. Soc. 2015, 137 (43), 13844-13850. 
https://doi.org/10.1021/jacs.5b06568.

(13) Klinkova, A.; De Luna, P.; Dinh, C. T.; Voznyy, O.; Larin, E. M.; Kumacheva, E.; Sargent, E. H. Rational Design of Efficient Palladium Catalysts for Electroreduction of Carbon Dioxide to Formate. ACS Catalysis 2016, 6 (12), 8115-8120. https://doi.org/10.1021/acscatal.6b01719.

(14) Jia, M.; Choi, C.; Wu, T.-S.; Ma, C.; Kang, P.; Tao, H.; Fan, Q.; Hong, S.; Liu, S.; Soo, Y.-L.; Jung, Y.; Qiu, J.; Sun, Z. Carbon-Supported Ni Nanoparticles for Efficient $\mathrm{CO}_{2}$ Electroreduction. Chem. Sci. 2018, 9 (47), 8775-8780. https://doi.org/10.1039/C8SC03732A.

(15) Wang, M.; Torbensen, K.; Salvatore, D.; Ren, S.; Joulié, D.; Dumoulin, F.; Mendoza, D.; Lassalle-Kaiser, B.; Işci, U.; Berlinguette, C. P.; Robert, M. CO2 Electrochemical Catalytic Reduction with a Highly Active Cobalt Phthalocyanine. Nat Commun 2019, 10(1), 3602. https://doi.org/10.1038/s41467-019-11542-w.

(16) Wu, D.; Wang, X.; Shi, L.; Jiang, K.; Wang, M.; Lu, C.; Chen, Z.; Liu, P.; Zhang, J.; Tranca, D.; Hou, Y.; Chen, Y.; Zhuang, X. Iron Clusters Boosted Performance in Electrocatalytic Carbon Dioxide Conversion. J. Mater. Chem. A 2020, 8 (41), 21661-21667. https://doi.org/10.1039/D0TA07867K.

(17) Yu, L.; Xie, Y.; Zhou, J.; Li, Y.; Yu, Y.; Ren, Z. Robust and Selective Electrochemical Reduction of $\mathrm{CO}_{2}$ : The Case of Integrated 3D TiO $2 @ \mathrm{MoS}_{2}$ Architectures and Ti-S Bonding Effects. J. Mater. Chem. A 2018, 6 (11), 4706-4713. https://doi.org/10.1039/C7TA11376E.

(18) Jiang, X.; Cai, F.; Gao, D.; Dong, J.; Miao, S.; Wang, G.; Bao, X. Electrocatalytic Reduction of Carbon Dioxide over Reduced Nanoporous Zinc Oxide. Electrochemistry Communications 2016, 68, 67-70. https://doi.org/10.1016/j.elecom.2016.05.003.

(19) Zhang, S.; Kang, P.; Meyer, T. J. Nanostructured Tin Catalysts for Selective Electrochemical Reduction of Carbon Dioxide to Formate. J. Am. Chem. Soc. 2014, 136 (5), 1734-1737. https://doi.org/10.1021/ja4113885.

(20) Ávila-Bolívar, B.; García-Cruz, L.; Montiel, V.; Solla-Gullón, J. Electrochemical Reduction of $\mathrm{CO} 2$ to Formate on Easily Prepared Carbon-Supported Bi Nanoparticles. Molecules 2019, 24 (11), 2032. https://doi.org/10.3390/molecules24112032.

(21) Xiao, X.; Xu, Y.; Lv, X.; Xie, J.; Liu, J.; Yu, C. Electrochemical CO2 Reduction on Copper Nanoparticles-Dispersed Carbon Aerogels. Journal of Colloid and Interface Science 2019, 545, 1-7. https://doi.org/10.1016/j.jcis.2019.03.005.

(22) Kim, D.; Kley, C. S.; Li, Y.; Yang, P. Copper Nanoparticle Ensembles for Selective Electroreduction of $\mathrm{CO}_{2}$ to $\mathrm{C}_{2}-\mathrm{C}_{3}$ Products. Proc Natl Acad Sci USA 2017, 114 (40), 10560-10565. https://doi.org/10.1073/pnas.1711493114.

(23) Kuhl, K. P.; Cave, E. R.; Abram, D. N.; Jaramillo, T. F. New Insights into the Electrochemical Reduction of Carbon Dioxide on Metallic Copper Surfaces. Energy and Environmental Science 2012, 5 (5), 7050-7059. https://doi.org/10.1039/c2ee21234j.

(24) Mistry, H.; Varela, A. S.; Bonifacio, C. S.; Zegkinoglou, I.; Sinev, I.; Choi, Y. W.; Kisslinger, K.; Stach, E. A.; Yang, J. C.; Strasser, P.; Cuenya, B. R. Highly Selective Plasma-Activated Copper Catalysts for Carbon Dioxide Reduction to Ethylene. Nature Communications 2016, 7. https://doi.org/10.1038/ncomms12123.

(25) Li, Y.; Cui, F.; Ross, M. B.; Kim, D.; Sun, Y.; Yang, P. Structure-Sensitive CO2 Electroreduction to Hydrocarbons on Ultrathin 5-Fold Twinned Copper Nanowires. Nano Letters 2017, 17 (2), 1312-1317. https://doi.org/10.1021/acs.nanolett.6b05287.

(26) Hammarstrom, J. M.; Zientek, M. L.; Parks, H. L.; Dicken, C. L. Assessment of Undiscovered Copper Resources of the World, 2015; Scientific Investigations Report; USGS Numbered Series 2018-5160; U.S. Geological Survey: Reston, VA, 2019; p 644. 
(27) Zhu, D. D.; Liu, J. L.; Qiao, S. Z. Recent Advances in Inorganic Heterogeneous Electrocatalysts for Reduction of Carbon Dioxide. Advanced Materials. Wiley-VCH Verlag May 11, 2016, pp 3423-3452. https://doi.org/10.1002/adma.201504766.

(28) Yang, K. D.; Ko, W. R.; Lee, J. H.; Kim, S. J.; Lee, H.; Lee, M. H.; Nam, K. T. MorphologyDirected Selective Production of Ethylene or Ethane from CO2 on a $\mathrm{Cu}$ Mesopore Electrode. Angewandte Chemie International Edition 2017, 56 (3), 796-800. https://doi.org/10.1002/anie.201610432.

(29) Shen, S.; He, J.; Peng, X.; Xi, W.; Zhang, L.; Xi, D.; Wang, L.; Liu, X.; Luo, J. Stepped Surface-Rich Copper Fiber Felt as an Efficient Electrocatalyst for the CO2RR to Formate. Journal of Materials Chemistry A 2018, 6 (39), 18960-18966. https://doi.org/10.1039/c8ta04758h.

(30) Yang, Y.; White, M. G.; Liu, P. Theoretical Study of Methanol Synthesis from CO 2 Hydrogenation on Metal-Doped $\mathrm{Cu}(111)$ Surfaces. Journal of Physical Chemistry C 2012, 116 (1), 248-256. https://doi.org/10.1021/jp208448c.

(31) Dean, J.; Yang, Y.; Austin, N.; Veser, G.; Mpourmpakis, G. Design of Copper-Based Bimetallic Nanoparticles for Carbon Dioxide Adsorption and Activation. ChemSusChem 2018, 11 (7), 1169-1178. https://doi.org/10.1002/cssc.201702342.

(32) Xiong, W.; Yang, J.; Shuai, L.; Hou, Y.; Qiu, M.; Li, X.; Leung, M. K. H. CuSn Alloy Nanoparticles on Nitrogen-Doped Graphene for Electrocatalytic $\mathrm{CO}_{2}$ Reduction. ChemElectroChem 2019, 6 (24), 5951-5957. https://doi.org/10.1002/celc.201901381.

(33) Reske, R.; Mistry, H.; Behafarid, F.; Roldan Cuenya, B.; Strasser, P. Particle Size Effects in the Catalytic Electroreduction of $\mathrm{CO} 2$ on Cu Nanoparticles. Journal of the American Chemical Society 2014, 136 (19), 6978-6986. https://doi.org/10.1021/ja500328k.

(34) Yang, B.; Liu, C.; Halder, A.; Tyo, E. C.; Martinson, A. B. F.; Seifert, S.; Zapol, P.; Curtiss, L. A.; Vajda, S. Copper Cluster Size Effect in Methanol Synthesis from CO 2. Journal of Physical Chemistry C 2017, 121 (19), 10406-10412. https://doi.org/10.1021/acs.jpcc.7b01835.

(35) Duan, Y.-X.; Meng, F.-L.; Liu, K.-H.; Yi, S.-S.; Li, S.-J.; Yan, J.-M.; Jiang, Q. Amorphizing of $\mathrm{Cu}$ Nanoparticles toward Highly Efficient and Robust Electrocatalyst for $\mathrm{CO} 2$ Reduction to Liquid Fuels with High Faradaic Efficiencies. Advanced Materials 2018, 1706194, 1706194. https://doi.org/10.1002/adma.201706194.

(36) Nadagouda, M. N.; Varma, R. S. Synthesis of Thermally Stable Carboxymethyl Cellulose/Metal Biodegradable Nanocomposites for Potential Biological Applications. Biomacromolecules 2007, 8 (9), 2762-2767. https://doi.org/10.1021/bm700446p.

(37) Zhou, R.; Wu, X.; Hao, X.; Zhou, F.; Li, H.; Rao, W. Influences of Surfactants on the Preparation of Copper Nanoparticles by Electron Beam Irradiation. Nuclear Instruments and Methods in Physics Research, Section B: Beam Interactions with Materials and Atoms 2008, $266 \quad$ (4), 599-603. https://doi.org/10.1016/j.nimb.2007.11.040.

(38) Nasrollahzadeh, M.; Sajadi, S. M.; Khalaj, M. Green Synthesis of Copper Nanoparticles Using Aqueous Extract of the Leaves of Euphorbia Esula L and Their Catalytic Activity for Ligand-Free Ullmann-Coupling Reaction and Reduction of 4-Nitrophenol. RSC Advances 2014, 4 (88), 47313-47318. https://doi.org/10.1039/c4ra08863h.

(39) Muniz-Miranda, M.; Gellini, C.; Giorgetti, E. Surface-Enhanced Raman Scattering from Copper Nanoparticles Obtained by Laser Ablation. Journal of Physical Chemistry C 2011, 115 (12), 5021-5027. https://doi.org/10.1021/jp1086027.

(40) Jianfeng, Y.; Guisheng, Z.; Anming, H.; Zhou, Y. N. Preparation of PVP Coated Cu NPs and the Application for Low-Temperature Bonding. J. Mater. Chem. 2011, 21 (40), 15981-15986. https://doi.org/10.1039/C1JM12108A. 
(41) Jeong, S.; Woo, K.; Kim, D.; Lim, S.; Kim, J. S.; Shin, H.; Xia, Y.; Moon, J. Controlling the Thickness of the Surface Oxide Layer on $\mathrm{Cu}$ Nanoparticles for the Fabrication of Conductive Structures by Ink-Jet Printing. Advanced Functional Materials 2008, 18(5), 679-686. https://doi.org/10.1002/adfm.200700902.

(42) Kobayashi, Y.; Sakuraba, T. Silica-Coating of Metallic Copper Nanoparticles in Aqueous Solution. Colloids and Surfaces A: Physicochemical and Engineering Aspects 2008, 317 (1), 756-759. https://doi.org/10.1016/j.colsurfa.2007.11.009.

(43) Jeong, S.; Song, H. C.; Lee, W. W.; Lee, S. S.; Choi, Y.; Son, W.; Kim, E. D.; Paik, C. H.; Oh, S. H.; Ryu, B.-H. Stable Aqueous Based Cu Nanoparticle Ink for Printing Well-Defined Highly Conductive Features on a Plastic Substrate. Langmuir 2011, 27 (6), 3144-3149. https://doi.org/10.1021/la104136w.

(44) Kim, Y. H.; Kang, Y. S.; Lee, W. J.; Jo, B. G.; Jeong, J. H. Synthesis of Cu Nanoparticles Prepared by Using Thermal Decomposition of Cu-Oleate Complex. Molecular Crystals and Liquid Crystals 2006, 445 (1), 231/[521]-238/[528]. https://doi.org/10.1080/15421400500366522.

(45) Giordano, C.; Corbiere, T. A Step Forward in Metal Nitride and Carbide Synthesis: From Pure Nanopowders to Nanocomposites. Colloid and Polymer Science 2013, 291 (6), 1297-1311. https://doi.org/10.1007/s00396-012-2865-x.

(46) Pappijn; Ruitenbeek; Reyniers; Geem. Challenges and Opportunities of Carbon Capture and Utilization: Electrochemical Conversion of $\mathrm{CO} 2$ to Ethylene. Front. Energy Res. 2020, 8, 245. https://doi.org/10.3389/fenrg.2020.557466.

(47) Todorova, T. K.; Schreiber, M. W.; Fontecave, M. Mechanistic Understanding of $\mathrm{CO}_{2}$ Reduction Reaction (CO2RR) Toward Multicarbon Products by Heterogeneous Copper-Based Catalysts. ACS Catal. 2020, 10 (3), 1754-1768. https://doi.org/10.1021/acscatal.9b04746.

(48) Hoang, T. T. H.; Ma, S.; Gold, J. I.; Kenis, P. J. A.; Gewirth, A. A. Nanoporous Copper Films by Additive-Controlled Electrodeposition: $\mathrm{CO}_{2}$ Reduction Catalysis. ACS Catal. 2017, 7(5), 3313-3321. https://doi.org/10.1021/acscatal.6b03613.

(49) Li, Q.; Zhu, W.; Fu, J.; Zhang, H.; Wu, G.; Sun, S. Controlled Assembly of Cu Nanoparticles on Pyridinic-N Rich Graphene for Electrochemical Reduction of CO2 to Ethylene. Nano Energy 2016, 24, 1-9. https://doi.org/10.1016/j.nanoen.2016.03.024.

(50) Kas, R.; Kortlever, R.; Yllmaz, H.; Koper, M. T. M.; Mul, G. Manipulating the Hydrocarbon Selectivity of Copper Nanoparticles in $\mathrm{CO} 2$ Electroreduction by Process Conditions. ChemElectroChem 2015, 2(3), 354-358. https://doi.org/10.1002/celc.201402373.

(51) Loiudice, A.; Lobaccaro, P.; Kamali, E. A.; Thao, T.; Huang, B. H.; Ager, J. W.; Buonsanti, R. Tailoring Copper Nanocrystals towards C2 Products in Electrochemical CO2 Reduction. Angewandte Chemie International Edition 2016, 55 (19), 5789-5792. https://doi.org/10.1002/anie.201601582.

(52) Wang, Y.; Shen, H.; Livi, K. J. T.; Raciti, D.; Zong, H.; Gregg, J.; Onadeko, M.; Wan, Y.; Watson, A.; Wang, C. Copper Nanocubes for CO2 Reduction in Gas Diffusion Electrodes. Nano Lett. 2019, 19 (12), 8461-8468. https://doi.org/10.1021/acs.nanolett.9b02748.

(53) Chen, Y.; Fan, Z.; Wang, J.; Ling, C.; Niu, W.; Huang, Z.; Liu, G.; Chen, B.; Lai, Z.; Liu, X.; Li, B.; Zong, Y.; Gu, L.; Wang, J.; Wang, X.; Zhang, H. Ethylene Selectivity in Electrocatalytic $\mathrm{CO}_{2}$ Reduction on $\mathrm{Cu}$ Nanomaterials: A Crystal Phase-Dependent Study. J. Am. Chem. Soc. 2020, 142 (29), 12760-12766. https://doi.org/10.1021/jacs.0c04981.

(54) Jeon, H. S.; Kunze, S.; Scholten, F.; Roldan Cuenya, B. Prism-Shaped Cu Nanocatalysts for Electrochemical CO 2 Reduction to Ethylene. ACS Catal. 2018, 8 (1), 531-535. 
https://doi.org/10.1021/acscatal.7b02959.

(55) Baturina, O. A.; Lu, Q.; Padilla, M. A.; Xin, L.; Li, W.; Serov, A.; Artyushkova, K.; Atanassov, P.; Xu, F.; Epshteyn, A.; Brintlinger, T.; Schuette, M.; Collins, G. E. CO2 Electroreduction to Hydrocarbons on Carbon-Supported Cu Nanoparticles. ACS Catal. 2014, 4 (10), 3682-3695. https://doi.org/10.1021/cs500537y.

(56) Choi, C.; Cheng, T.; Espinosa, M. F.; Fei, H.; Duan, X.; Goddard, W. A.; Huang, Y. A Highly Active Star Decahedron $\mathrm{Cu}$ Nanocatalyst for Hydrocarbon Production at Low Overpotentials. Advanced Materials 2019, 31 (6), 1805405. https://doi.org/10.1002/adma.201805405. 